\title{
Corneal and Scleral Dellen after an Uneventful Pterygium Surgery and a Febrile Episode
}

\author{
Massimo Accorinti Marta Gilardi Marco Giubilei \\ Daniele De Geronimo Ludovico Iannetti \\ Ocular Immunovirology Service, Department of Ophthalmology, Sapienza University of \\ Rome, Rome, Italy
}

\section{Key Words}

Corneal dellen · Scleral dellen $\cdot$ Pterygium $\cdot$ Fever

\begin{abstract}
Introduction: We describe a patient with corneal and scleral dellen, which occurred after an uneventful pterygium excision without adjunctive therapy and a subsequent febrile episode. Case Report: A 43-year-old woman presented with a history of recurrent irritation in her right eye and a diagnosis of pterygium. The pterygium was excised under local anesthesia with the bare scleral technique and without the use of antimetabolites. No complications occurred until 14 days after surgery when corneal and sclera dellen appeared; this was 2 days after a concomitant febrile episode $\left(39^{\circ} \mathrm{C}\right)$. Tobramycin and dexamethasone eye drops given after surgery were withdrawn and topical lubricants and antibiotic ointment, in combination with oral L-amino acids, were administered along with eye patching. One week later, the corneal dellen had completely healed and, 4 weeks later, the thinned sclera appeared regularly thick and white in color. Three months after surgery, a small recurrent pterygium was diagnosed, which remained stable without signs of inflammation for additional 18 months. Conclusions: Corneal and scleral dellen might be a late complication of uneventful pterygium surgery without antimetabolites and a subsequent febrile episode.
\end{abstract}

(C) 2014 S. Karger AG, Basel

\section{Introduction}

Corneal dellen are small saucer-like excavations at the margin of the cornea. They occur most often following processes which produce a paralimbal elevation that is able to induce a 
Accorinti et al:: Corneal and Scleral Dellen after an Uneventful Pterygium Surgery and a Febrile Episode

localized break in the precorneal oily layer of the tears which, in turn, causes a localized dehydration and thinning of the cornea. Corneal dellen are located near areas of tissue growth, inflammation or eyelid abnormality and they are most often due to pterygium surgery, large filtration blebs, dermoids, scleritis, episcleritis, scarring after extraocular muscle surgery or severe conjunctival chemosis.

Patients complain about redness, foreign body sensation and mild discomfort. Under slit-lamp examination, a depressed area with sharply defined edges with a dull center normally no larger than 2-3 $\mathrm{mm}$ becomes visible. The lesions are characterized by an intact epithelium overlying a thinned area of dehydrated corneal stroma. Most often, dellen are transient, lasting 24-48 h; occasionally, they may become chronic with an associated breakdown of the epithelium and stromal inflammation with tissue loss and scarring. Overall, corneal dellen usually heal within 10-15 days [1]. Treatment consists of a reduction or elimination of the contributing perilimbar elevation and a rapid rehydration with artificial tears, eye ointment and patching [2]. In some cases, even a contact lens can be used to support the repairing process. If treated promptly, dellen usually resolve completely without any permanent sequelae.

Scleral dellen result from local dehydration and thinning of the sclera tissues with exposure of the underlying uvea leading to their bluish color. This condition has been reported to occur after a variety of ocular surgical procedures, including strabismus surgery, pterygium excision (with or without the use of adjunctive treatment such as beta radiation, conjunctival autograft and mitomycin C) and cataract extraction [3, 4]. Among the complication of pterygium surgery, corneoscleral dellen have been rarely reported, especially without the use of adjunctive therapy.

We report a case of severe corneoscleral dellen that occurred 14 days after the uneventful surgical excision of primary pterygium and 2 days after the occurrence of a febrile episode.

\section{Patient and Methods}

A 43-year-old woman presented with a history of recurrent redness and foreign body sensation in her right eye. Ophthalmologic examination disclosed the presence of a nasal pterygium, measuring $3 \mathrm{~mm}$ at the limbus and $3 \mathrm{~mm}$ into the cornea. Slit-lamp examination revealed no other abnormality in the eye, neither was there any clinical evidence of dry eye. Her ocular and medical histories were unremarkable. The patient was scheduled for pterygium surgery.

\section{Results}

The pterygium was excised under local anesthesia. Briefly, the head was separated at the limbus and then lifted off the corneal surface by blunt dissection. After excising the head and the body of the pterygium, a conjunctival suture was made leaving $2 \mathrm{~mm}$ of bare sclera. At the end of the surgery, a combination therapy with dexamethasone $0.1 \%$ and tobramycin $0.3 \%$ was given and the right eye was patched. On the first postoperative day and 7 days thereafter, no complaints or complications were noted. The patient was treated with the combination therapy 4 times daily for the first week and 3 times daily for the second week. Two weeks after surgery, and 2 days after the onset of a flu-like syndrome with fever $\left(39^{\circ} \mathrm{C}\right)$, the patient noticed a small painless dark area at the surgical site. No conjunctival discharge 
Accorinti et al:: Corneal and Scleral Dellen after an Uneventful Pterygium Surgery and a Febrile Episode

was reported. Slit-lamp examination revealed no conjunctival papillary or follicular reaction in the fornices, no discharge, no ciliary injection, but a corneal dellen with a focal area of sclera thinning measuring $2 \times 2 \mathrm{~mm}$ surrounded by edematous conjunctiva (fig. 1). The thinned sclera appeared dry and the bluish subjacent uvea was visible through the base of the lesion.

Corneoscleral dellen were diagnosed, and an infectious cause of the lesion was ruled out upon clinical findings. The eye was patched, and the eye drops combination therapy was withdrawn; topical lubricants 8 times daily and tetracycline ointment 4 times daily were given, along with 3 tablets daily of a mix of L-amino acids (Aminoftal ${ }^{\circledR}$ ).

One week later, the corneal dellen had completely healed. Four weeks later, the thinned sclera appeared regularly thick and white in color (fig. 2). At that time, no clinical signs of dry eye were present, and break-up time and Schirmer's tests were within normal limits.

Three months after surgery, a recurrence of the pterygium measuring $1 \mathrm{~mm}$ into the cornea was diagnosed in the right eye and a therapy with a tear-film substitute was prescribed. Twenty-two months after surgery, no further pterygium progression nor inflammation was present, and the patient was free of any systemic disease.

\section{Discussion}

The surgical excision of the pterygium is a commonly performed procedure with complication rates ranging from 0 to $26 \%$ [5]. Scleral dellen have been rarely reported among the complications that might arise after primary pterygium excision with or without adjunctive therapy [6, 7]. The bare scleral technique for pterygium surgery, leaving for some time a denudated sclera, might theoretically favor the onset of corneal dellen, if there are concomitant significant conjunctival edema inhibiting a normal tear distribution over the cornea, and if there is a decreased tear production. This was not the case in our patient. She was otherwise healthy. No conditions predisposing to ulceration, poor wound healing or decreased tear production were present, such as Sjögren's Syndrome, keratoconjunctivitis sicca, acne rosacea, atopic keratoconjunctivitis or herpes keratitis, an autoimmune disease or vasculitis. Nor was she treated with adjunctive substances (e.g. mitomycin C) during surgery that might prompt the onset of dellen. Furthermore, no systemic diseases and especially no autoimmune processes or vasculitis that might be associated with the onset of corneal and scleral damage [8] have been diagnosed during the 22 months of follow-up.

However, it is well-known that temperature plays a major role in ocular surface alterations $[9,10]$. Particularly patients with pterygium might present a break-up time test reduction as well as an instability of the tear-film layer which worsens the tear-fluid evaporation [10]. A similar alteration can be hypothesized in patients recently operated on for pterygium excision. In our patient, the onset of a flu-like syndrome, with a relatively high temperature, might have caused further dehydration, associated with tear-film instability and reduction. The acute dehydration associated with the febrile episode seems to be the promoting factor favoring the onset of the corneal and scleral dellen, along with the paralimbal elevation. In fact, corneoscleral dellen occurred 2 weeks after surgery in our patient, while dellen very rarely occur after pterygium surgery so late $[6,7]$.

The corneoscleral dellen rapidly improved after topical hydration therapy with tear-film substitutes, antibiotic ointment and eye patching. We have also given the patient a mix of Lamino acids, which has been demonstrated to be useful to promote the healing of different ocular tissue such as conjunctiva and cornea [11]. In conclusion, corneal and scleral dellen might occur even late after uneventful pterygium surgery performed without adjunctive 


\begin{tabular}{l|l}
\hline Case Rep Ophthalmol 2014;5:111-115 \\
\hline DOI: $10.1159 / 000362156$ & $\begin{array}{l}\text { @ 2014 S. Karger AG, Basel } \\
\text { www.karger.com/cop }\end{array}$ \\
\hline
\end{tabular}

Accorinti et al:: Corneal and Scleral Dellen after an Uneventful Pterygium Surgery and a Febrile Episode

therapies, such as mitomycin $\mathrm{C}$, which might be responsible for a delayed conjunctival healing [12], especially if other predisposing conditions, such as a febrile episode, are concomitant.

\section{Disclosure Statement}

None of the authors has any financial interest in the information presented in this case report.

\section{References}

1 Fresina M, Campos EC: Corneal dellen as a complication of strabismus surgery. Eye 2009;23:161-163.

-2 Walkow T, Daniel J, Meyer CH, Rodrigues EB, Mennel S: Long-term results after bare sclera pterygium resection with excimer smoothing and local application of mitomycin C. Cornea 2005;24:378-381.

-3 Kymionis GD, Plaka A, Kontadakis GA, Astyrakakis N: Treatment of corneal dellen with a large diameter soft contact lens. Cont Lens Anterior Eye 2011;34:290-292.

7 Chen S, Noonan C: Scleral dellen complicating primary pterygium excision. Eye 2000;14:100-101.

5 Mitra S, Ganesh A, Shenoy R: Scleral dellen complicating primary pterygium excision. Eye 2000;14:924-925.

-6 Tsai YY, Lin JM, Shy JD: Acute scleral thinning after pterygium excision with intraoperative mitomycin C: a case report of scleral dellen after bare sclera technique and review of the literature. Cornea 2002;21:227229.

7 Safianik B, Ben-Zion I, Garzozi HJ: Serious corneoscleral complications after pterygium excision with mitomycin C. Br J Ophthalmol 2002;86:357-358.

8 Yagci A: Update on peripheral ulcerative keratitis. Clin Ophthalmol 2012;6:747-754.

-9 Kamao T, Yamaguchi M, Kawasaki S, Mizoue S, Shiraishi A, Ohashi Y: Screening for dry eye with newly developed ocular surface thermographer. Am J Ophthalmol 2011;151:782-791.

10 Gonnermann J, Maier AKB, Klein JP, Bertelmann E, Pleyer U, Klamann MK: Evaluation of ocular surface temperature in patients with pterygium. Curr Eye Res 2014;39:359-364.

-11 Torres Munoz I, Grizzi F, Russo C, Camesasca FI, Dioguardi N, Vinciguerra P: The role of amino acids in corneal stromal healing: a method for evaluating cellular density and extracellular matrix distribution. J Refract Surg 2003;19(suppl):S227-S230.

12 Kaufman SC, Jacobs DS, Lee WB, Deng SX, Rosenblatt MI, Shtein RM: Options and adjuvants in surgery for pterygium: a report by the American Academy of Ophthalmology. Ophthalmology 2013;120:201-208.

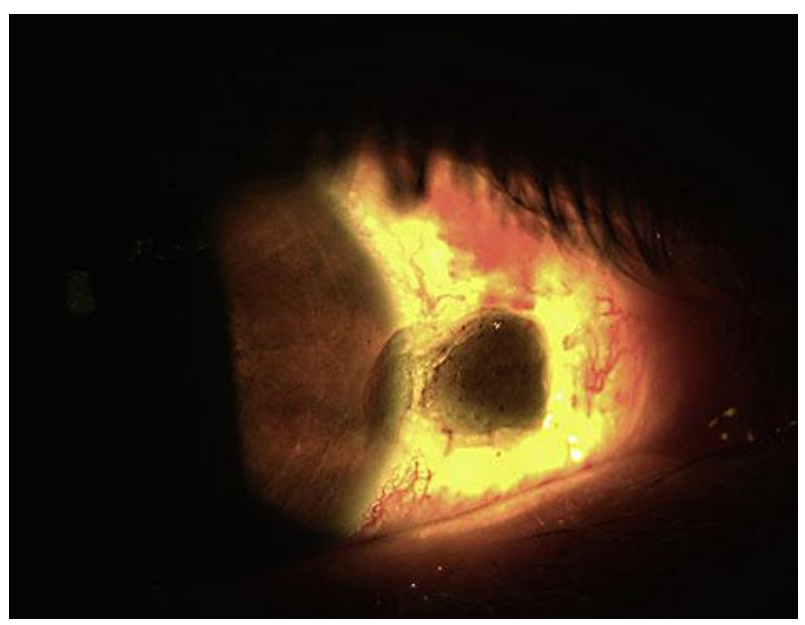

Fig. 1. Corneal and scleral dellen at the onset. 
Case Reports in

Ophthalmology
Case Rep Ophthalmol 2014;5:111-115

DOI: 10.1159/000362156

Accorinti et al.: Corneal and Scleral Dellen after an Uneventful Pterygium Surgery and

a Febrile Episode

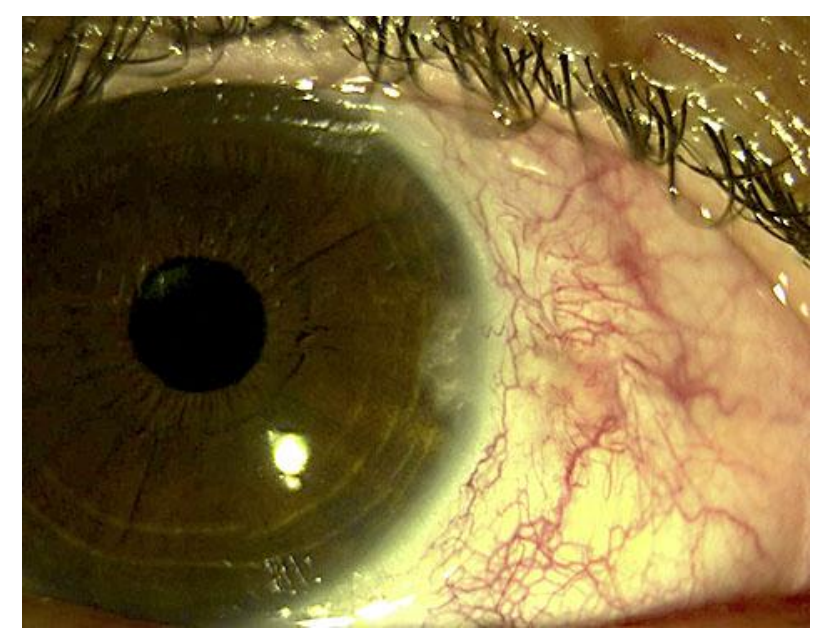

Fig. 2. Complete healing of corneoscleral dellen occurred 4 weeks after the onset. 